\section{International Scientific Journal Theoretical \& Applied Science}

\author{
p-ISSN: 2308-4944 (print) e-ISSN: 2409-0085 (online) \\ Year: 2017 Issue: 02 Volume: 46
}

Published: $28.02 .2017 \quad$ http://T-Science.org
Sergey Alexandrovich Mishchik

Associate Professor,

Candidate of Pedagogical Science,

Academician of International Academy TAS,

Assistant professor Department of Physics,

State Maritime University Admiral Ushakov, Russia, sergei_mishik@mail.ru

SECTION 21. Pedagogy. Psychology. Innovation in Education.

\title{
DEVELOPMENT DATABASE OF PEDAGOGOMETRIC MODELS FORMED ERTSGAMMING ANALYSIS OF EDUCATIONAL FACILITIES
}

Abstract: The basic directions of development database pedagogometric models Forming ertsgamming analysis of educational facilities in the formation of mathematical vogueley learning activities about the nature of achieving the criteria of life, cyclicness, consistency and phasing, which form the basic cell education space, as well as the use of the twelve pointed star Ertsgammy for the submission ertsgamming principle which determines the foundations pedagogometric through substantive shaping metodami hyperspace professional life, psychological and educational activity theory, psycho-pedagogical system analysis and the theory of the formation of mental dei Business Plan.

Key words: database, forming ertsgamming analysis, educational facility, pedagogometric, lifeactivity, recurrence, systemic, stages, star Ertsgammy.

Language: Russian

Citation: Mishchik SA (2017) DEVELOPMENT DATABASE OF PEDAGOGOMETRIC MODELS FORMED ERTSGAMMING ANALYSIS OF EDUCATIONAL FACILITIES. ISJ Theoretical \& Applied Science, 02 (46): 180-185.

Soi: http://s-o-i.org/1.1/TAS-02-46-30 Doi: crossef https://dx.doi.org/10.15863/TAS.2017.02.46.30

УДК 372.851

\section{РАЗВИТИЕ БАЗЫ ДАННЫХ ПЕДАГОГОМЕТРИЧЕСКИХ МОДЕЛЕЙ ФОРМИРУЮЩЕГО ЭРЦГАММНОГО АНАЛИЗА ОБРАЗОВАТЕЛЬНЫХ ОБЬЕКТОВ}

Аннотация: Рассмотрены основные направления развития базы данных педагогометрических моделей формирующего эригаммного анализа образовательных объектов при формировании математических моделей учебной деятельности относительно характера достижения критериев жизнедеятельности, ичиклиности, системности и этапности, которые образуют базисную ячейку образовательного пространства, а также применение двенадиати конечной звезды Эригаммы относительно представления принципа эригаммности, который определит основы педагогометрики через формообразование предметными методами гиперпространства профессиональной жизнедеятельности, психолого-педагогической теории деятельности, психолого-педагогического системного анализа и теории формирования умственных действий.

Ключевье слова: база данных, формируюший эризгаммный анализ, образовательный объект, педагогометрика, жизнедеятельность, циикличость, системность, этапность, звезда Эригаммы.

\section{Introduction}

Развитие формирования базы данных педагогометрических моделей формирующего эрцгаммного анализа образовательных объектов при формировании математических моделей учебной деятельности относительно характера достижения критериев жизнедеятельности, цикличности, системности и этапности, которые образуют базисную ячейку образовательного пространства. Это проявляется в организации развития базы данных математических моделей относительно уровня проявления в учебном процессе: базисной звезды Эрцгаммы гиперпространства жизнедеятельности (E1); базисного целостно-системного цикла жизнедеятельности $\quad$ (E2); базисной 
Эрцгаммы системного анализа (Е3); базисного проявления двенадцати этапов и форм познавательного жизнедеятельности гиперпространства относительно образовательного процесса (E4).

Развитие каждой базы данных педагогометрических моделей формирующего эрцгаммного анализа образовательных объектов с признаком базисно-нормативной эрцгаммности, независимо от целевого назначения, выполняет собственную функцию психологоматематического представления, имеющего соответствующий показатель базиснонормативного целостного развития относительно характеристик собственной значимости. Каждый базисно-нормативный глобальный объект (E1N, E2N, E3N, E4N) образовательного пространства выполняет синфазно три сравнительные функции: ориентировки, исполнения и контроля собственной фазы развития образовательного процесса относительно нормативной учебнопрофессиональной деятельности эрцгаммного типа. Поэтому можно организовать развитие представления базы данных педагогометрических моделей формирующего эрцгаммного анализа образовательных объектов при эрцгаммном контроле педагогометрического исследования образовательных объектов, выражающего степень многофазного развития всех составляющих процессов формирования студентов. При этом можно представить шестиэтапную модель базисного действия, состоящего из смыслообразование действия; принятие действия; ориентировочной части действия; исполнительной части действия; контрольная части действия и прогноза развития действия представляющего инвариантную основу образовательной активности[10]. При этом решаются сорок восемь задач формирования целостно-системной личности. Процесс решения каждой задачи разворачивается относительно реализации базисной звезды Эрцгаммы гиперпространства жизнедеятельности (Е1); базисного целостно-системного цикла жизнедеятельности (E2); базисной звезды Эрцгаммы системного анализа (Е3); базисного проявления двенадцати этапов и форм познавательного гиперпространства жизнедеятельности относительно образовательного процесса (E4).

\section{Materials and Methods}

Развитие базы данных педагогометрических моделей формирующего эрцгаммного анализа образовательных объектов при формировании математических моделей учебной деятельности относительно способа достижения критериев эрцгаммности на различных целостно-системных представлениях о профессиональной практической деятельности связывается с различными информационными представлениями об ориентировочных, исполнительных и контрольных качествах технологических процессов [10].

Развитие базы данных педагогометрических моделей формирующего эрцгаммного анализа образовательных объектов относительно формирующего педагогометрического математического моделирования учебного процесса связывается с проблемой повышения эффективности управления учебной деятельности студентов на основе игрового автоматизированного обучающего комплекса. Динамизм изменения учебной обстановки, неопределенность и неполнота поступающих данных, сокращение времени на реагирование, многоплановость и многовариантность решения задач учебной деятедьност требуют поиска новых форм компьютерных обучающих программ, имитационных систем, тренажеров. При этом разрабатываются концептуальные положения и обобщенная функционально-структурная схема игрового автоматизированного обучающего комплекса (ИАОК). В результате происходит: разработка математических моделей представления данных в информационной базе ИАОК; формирование обобщенной модели гипермедийной информационной базы на основе нечетких когнитивных карт; использование теорий: управления в организационнотехнических системах, нечетких множеств и логики, теории графов, системного анализа, синтеза баз данных, знаний, исследования операций. Математическая модель описания оперативных учебных ситуаций на основе нечетких когнитивных карт, позволяет применение статического нечеткого графа в случае представления в информационной базе стереотипных учебных ситуаций и нечеткого динамического графа, отражающего изменение оперативной или наличие нестереотипной ситуации учебной деятельности [1].

Развитие базисных формирующих педагогометрических математических моделей учебной деятельности также определяется проблемой разработки методов и алгоритмов оценки качества управления образовательным процессом и соответствующей учебной деятельностью. На основе системного и теоретико-множественного подхода решаются задачи с многоцелевых позиций и обеспечивается релевантность анализа, мониторинга и оценки качества управления. Выделены основные направления оценки качества управления учебной деятельностью: установление целей и нормативов учебной деятельности (ЦН), улучшение условий и технологий учебной деятельности (ТО), содержания образования 
(CO), результаты образования (РО), потребности общества в результатах учебной деятельности (ПО). Модель качества образовательного процесса представлена в виде кортежа $\mathrm{K}=<K_{ц H}$, $K_{T O}, K_{C O}, K_{P O}, K_{\Pi О}>$, где $K_{ц Н}, K_{T O}, K_{C O}, K_{P O}$,

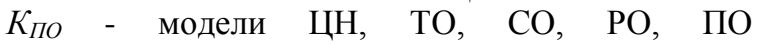
соответственно.

В основе построения структурной модели оценки качества управления учебной деятельностью используется системный подход, когда образовательный процесс рассматривается как совокупность компонентов и связей между ними. В качестве компонентов выделяются основные составляющие учебной деятельности. В результате декомпозиции модель представляется

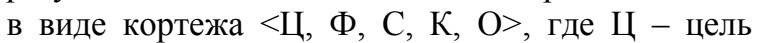
системы; Ф - функции системы; С - структура системы, которая реализует ее функции; К компоновка перечисленных элементов системы; $\mathrm{O}$ - организация функционирования системы [2].

Развитие и структуирование базисных формирующих педагогометрических математических моделей учебной деятельности позволяет анализировать методы и средства управления образовательной траекторией в системах электронного обучения на основе теории измерения латентных переменных, теории нечетких множеств, теории управления, методах математической статистики. Формируется математическая модель конструкта - «зона ближайшего развития», основанная на объективной градуировке учебных материалов по уровню трудности. Строится модель измерения уровня текущих учебных достижений на основе методологии Г. Раша с расширенным набором наблюдаемых индикаторов учебной деятельности, в который наряду с результатами выполнения тестовых заданий включены метрики взаимодействия обучающихся с учебным контентом, а также обработки метрик немонотонного характера, что позволяет использовать их для измерения уровня подготовленности наряду с монотонными метриками. Выделяется метод управления индивидуальной траекторией обучения, основанный на идеях кибернетического подхода к обучению Л.А. Растригина, что позволяет производить адаптивное формирование блока объектов учебного контента на каждом шаге обучения, учитывая уровень подготовленности обучающегося. Устанавливается структурнофункциональная организация системы электронного обучения, особенностью которой является модуль принятия решений по ветвлению траектории обучения, использующий информацию об индивидуальной зоне ближайшего развития студента [3].

Развитие и анализ базисных формирующих педагогометрических математических моделей учебной деятельности связывается с математическим и программным обеспечением поддержки принятия решений в системе учебной подготовки студентов. При этом разработана технология формирования мультисоциометрической образовательной компоненты (показателя готовности) на современном рынке труда в виде мнемокода, отражающего уровень готовности специалистов на основе оценок уровня компетентности относительно теоретических и практических знаний. Сформирована математическая модель и методика комплексной оценки подготовки специалистов на основе теории нечётких множеств и алгоритма рейтинговой оценки, представленной на энтропийном подходе, его математическое и программное обеспечение, позволяющее автоматизировать поддержку принятия управленческих решений. Основные результаты исследования по обеспечениею поддержки принятия решений получены с использованием теории управления организационными системами, теории принятия решений, а также методов управления качеством, аппарата теории нечётких множеств, теории вероятностей и математической статистики, экспертных оценок, методов структурного программирования [4].

Развитие базисных формирующих педагогометрических математических моделей учебной деятельности также определяется проблемой разработки модели и алгоритмов управления тренажной подготовкой студентов на основе теории системного и математического анализов; имитационного и компьютерного моделирования; теории автоматического управления и принятия решений; теории вероятности и математической статистики; теории поэтапного формирования умственных действий и понятий. При этом предложена системная модель организации тренажной подготовки специалистов, которую можно представить в виде трёх взаимосвязанных уровней: функционально-ориентированного предметно-ориентированного и проблемноориентированного. Для оценки качества имитируемой модели по энтропийному значению вариации ее переменных вводится понятие показателя качества модели по переменной, определяемой относительно равномерного закона распределения вероятностей. Адекватность результатов имитационного моделирования реального объекта устанавливается метрической мерой близости между выходными сигналами объекта и соответствующими им выходными сигналами модели, отражающими предметнодеятельные характеристики обучения [5].

Развитие и структуирование базисных формирующих педагогометрических 
математических моделей учебной деятельности позволяет анализировать модели и алгоритмы прогнозирования оценки качества объектов системы высшего образования на основе ретроспективной, текущей и экспертной информации. Разработан алгоритм получения критерия академической успешности, создания показателя академической успешности, на основе ретроспективной экспертной информации. Сформирован алгоритм создания текстовых индексов - трансформационных параметров текста и создана база данных параметров текста на основе ретроспективной текстовой информации. Представлены математические модели определения границы между уровнями качества подготовки специалистов, созданные с применением методов: регрессионного анализа и максимального правдоподобия, дающие прогнозировать оценку качества объектов образования через ретроспективную и текущую информацию [6].

Развитие и анализ базисных формирующих педагогометрических математических моделей учебной деятельности связывается с представлением модели и алгоритма управления подготовкой специалистов на основе интегрального мотивационного потенциала в условиях многопрофильного образования. На основе системного анализа, теории управления, системно-деятельностного подхода, многокритериального выбора, математической статистики, имитационного моделирования, теория алгоритмов, теории множеств, классифицирования, теории вероятностей: сформированы модель управления распределением времени студентов относительно системы бальных мотивационных контролирующих и воздействующих факторов, повышающих динамику усвоения учебного контента; введен интегральный мотивационный потенциал (ИМП), представляющий количественный показатель, который характеризует уровень мотивированности обучающихся; предложена модель совершенствования образовательного процесса на основе управления динамикой интегрального мотивационного потенциала при многопрофильном обучении [7] .

Развитие базисных формирующих педагогометрических математических моделей учебной деятельности также определяется проблемой разработки модели и алгоритма управления для нелинейной системы организации учебной деятельности. На основе моделирования организационных систем управления, системного анализа, теории игр, теории вероятности, теории принятия решений, использованием расплывчатых категорий: синтезирована модель системы управления учебным процессом позволяющая минимизировать возможность манипулирования информацией о типе кафедры; представлена задача построения оптимальной модели стимулирования профессиональной активности обеспечивающая повышение качества учебной деятельности; построен экспертный механизм для оценки сложности конкретного вида занятия из изучаемого тематического блока определяющий весовой коэффициент для построения системы расчета нагрузки учебной деятельности; разработана имитационная модель системы управления учебным процессом на основе трёх фазной Q-схемы с обратной связью оптимального взаимодействия [8].

Развитие и структуирование базисных формирующих педагогометрических математических моделей учебной деятельности позволяет моделировать и оптимизировать индивидуальную траекторию обучения студента (ИТОС) на основе методов системного анализа, интеллектуального анализа данных, предобработки данных, экспертных оценок, нейросетевого моделирования, динамического программирования, теории принятия решений. При этом проведён системный анализ существующих методов и алгоритмов оценки компетентности студента и моделирования ИТОС; разработана модель оценки компетентности с учетом результатов освоения основных образовательных программ, научноисследовательской работы, индивидуальных особенностей студента и требований ФГОС; сформирован алгоритм оценки компетентности студента на основе использования гибридных экспертных систем и методов предобработки данных; спроектированы модели оптимизации ИТОС на основании критерия максимизации уровня сформированности компетентности [9].

Развитие и анализ базисных формирующих педагогометрических математических моделей учебной деятельности связывается с представлением модели и алгоритмов управления подготовкой магистров на основе методов системного анализа, системно-деятельностного подхода, многокритериального выбора, математической статистики, теории алгоритмов, теории множеств, классифицирования, математического моделирования, теории графов, теории сетевого планирования. При этом установлены модели и алгоритмы системы управления подготовкой магистров технического профиля на основе компетентностного подхода; представлена модель оценки важности и эффективности при формировании компетенций выпускника магистратуры вуза; определён алгоритм управления организацией обучения с позиции компетентностного подхода, с учетом процедуры измерения факторов и уровней формирования компетенций по видам 
деятельности:

проектно-конструкторская; сервисно-эксплуатационная; научноисследовательская; организационноуправленческая; экспертная, надзорная и инспекционно-аудиторская с элементами математического моделирования компетенций [11].

Развитие педагогометрическое математическое процесса отражает общее направление автоматизаци образовательных технологий, направленных на совершенствование циклической, базисной, фундаментальной и широкопрофильной подготовки специалистов, которые должны ориентироваться в общей структуре производства, совокупности методов его самоорганизации и этапах формирования профессионального мастерства.

Развитие формирования базы данных педагогометрических моделей формиирующего эрцгаммного анализа образовательных объектов при формировании математических моделей учебной деятельности относительно способа достижения критериев эрцгаммности максимально достигается при анализ базисных педагогометрических математических моделей учебной деятельности на основе психологопедагогического системного анализа, психологической теории деятельности, теории формирования интеллекта, гиперпространства целостно-системных циклов жизнедеятельности эрцгамного формообразования. Целостносистемное учебное действие (ЦСУД) составляет базисную структурную основу целостносистемного цикла жизнедеятельности (ЦСЦЖ), состоящего из двенадцати компонентов звезды Эрцгаммы. Каждый элемент ЦСЦЖ можно представить методами системного анализа через двенадцать психолого-педагогических действий, которые в процессе интериоризации принимают двенадцать основных форм от ориентационной до внутренней и также имеют деятельностную основу. С учётом процессов коммуникативной деятельности дополнительно выделяются четыре целостно-системные учеб-ные действия. Существует сорок базисных ЦСУД, которые имеют предметно-деятельностную основу относительно ЦСЦЖ, психолого-педагогического системного анализа и процесса формирования интеллекта. Математическое моделирование целостно-системного учебного действия определяет базисную задачу педагогометрики [10].

Каждое целостно-системное учебное действие имеет три базисные компонента: ориентировочный, исполнительный и контрольный, которые определяют основные направления математического моделирования ЦСУД. Множество элементов учебного действия можно записать в виде набора последовательных элементов системных операций. Каждый элемент ЦСУД характеризуется конкретными свойствами, которые однозначно определяют его в данной системе. Совокупность всех свойств элемента учебного действия устанавливает его состояние. Между базисными компонентами ЦСУД констатируют связь - множество счётных зависимостей свойств между элементами системы учебного действия, составляющих ведущие компетенции. Это определяет собственную структуру развития каждой из сорока восьми задач формирования целостносистемной личности современного специалиста.

\section{Conclusion}

Поиск и анализ основных направлений развития формирования базы данных педагогометрических моделей формирующего эрцгаммного анализа образовательных объектов относительно педагогометрического формирующего математического моделирования учебного процесса связывается с процессами совершенствования программируемых математических моделей учебной деятельности относительно характера представления критериев жизнедеятельности, цикличности, системности и этапности, которые образуют базисную ячейку образовательного пространства, определяют условия развития абсолютного образовательного цикла, отражающего специфическую структуру подготовки широкопрофильных специалистов при реализации международных образовательных стандартов. При этом важно установить направление развитие и способы формирования уровня состояния основных базисных параметров всех основных четырёх структур целостносистемных звёзд Эрцгаммы, степень их взаимосвязи в направлении исследования шестиэлементной структуры базисного целостносистемного действия. Каждая задача формирования целостно-системной личности задаётся критериями достижения уровней мультипликативного пространства широкопрофильной деятельности через реализацию многофазных предметнодеятельностых отношений скоростных формирующих схем. 


\begin{tabular}{l|lrl|l|ll} 
& ISRA (India) & $=\mathbf{1 . 3 4 4}$ & SIS (USA) & $=\mathbf{0 . 9 1 2}$ & ICV (Poland) & $=\mathbf{6 . 6 3 0}$ \\
Impact Factor: & ISI (Dubai, UAE) $=\mathbf{0 . 8 2 9}$ & PUHU (Russia) $=\mathbf{0 . 2 3 4}$ & PIF (India) & $=\mathbf{1 . 9 4 0}$ \\
& GIF (Australia) & $\mathbf{0 . 5 6 4}$ & ESJI (KZ) & $=\mathbf{1 . 0 4 2}$ & IBI (India) & $\mathbf{4 . 2 6 0}$
\end{tabular}

\section{References:}

1. Katyhin AI (2012) Povyšenie èffektivnosti upravleniâ dejstviâmi podrazdelenij MČS na osnove igrovogo avtomatizirovannogo obučaûŝego kompleksa [Tekst]: dis. ... kand. teh. nauk: 05.13.10 / A.I.Katyhin. - Kursk, 2012. -164 p.

2. Korovina OV (2013) Razrabotka metodov i algoritmov ocenki kačestva upravleniâ obrazovatel'nym processom vysšego učebnogo zavedeniâ[Tekst]: avto-ref.dis. ... kand. teh. nauk: 05.13.10 / O.V. Korovina.- Voronež, 2013. - 16 p.

3. Kosonogova MA (2016) Metod i sredstva upravleniâ obrazovatel'noj traektoriej V sistemah èlektronnogo obučeniâ [Tekst]: dis. ... kand. teh. nauk: 05.13.10 / M. A.Kosonogova. Belgorod, 2016. - 160 p.

4. Krohaleva AB (2016) Matematičeskoe i programmnoe obespečenie podderžki prinâtiâ rešenij $\mathrm{v}$ sisteme podgotovki specialistov (na primere napravleniâ "informacionnaâ bezopasnost"') [Tekst]: avto-ref.dis. ... kand. teh. nauk: 05.13.10 / A.B.Krohaleva. Novosibirsk, 2016. - 23 p.

5. Kuatov BZ (2015) Modeli i algoritmy upravleniâ trenažnoj podgotovkoj kursantov letnyh special'nostej [Tekst]: avto-ref.dis. ... kand. teh. nauk: 05.13.10 / B. Ž.Kuatov.Penza, 2015. - 24 p.

6. Kuz'minova AV (2015) Modeli i algoritmy prognozirovaniâ ocenki kačestva ob"ektov sistemy vysšego obrazovaniâ na osnove retrospektivnoj, tekuŝej i èkspertnoj informacii[Tekst]: dis. ... kand. teh. nauk: 05.13.10 / A. V. Kuz'minova. Moskva, 2015. - $181 \mathrm{p}$.

7. Lifs̃ic EA (2013) Modeli i algoritmy upravleniâ podgotovkoj specialistov na osnove integral'nogo motivacionnogo potenciala $\mathrm{V}$ usloviâh mnogoprofil'nogo obrazovaniâ [Tekst]: avto-ref.dis. ... kand. teh. nauk: 05.13.10 / E.A.Lifs̃ic. - Moskva, 2013. - 26 p.

8. Lominogina EV (2008) Modeli upravleniâ dlâ nelinejnoj sistemy organizacii učebnogo processa vuza [Tekst]: dis. ... kand. teh. nauk: 05.13.10 / E.V.Lominogina. - Voronež, 2008. $136 \mathrm{p}$.

9. Mahnytkina OV (2013) Modelirovanie i optimizaciâ individual'noj traektorii obučeniâ studenta [Tekst]: avto-ref.dis. ... kand. teh. nauk: 05.13 .10 / O.V.Mahnytkina. Novosibirsk, 2013. $-23 \mathrm{p}$

10. Mishchik SA (2014) Mathematical modeling integrity - system performance subject - fourth task pedagogometriki. Materialy Mezhdunarodnoy nauchnoy konferenctsii "Eurapean Science and Technology" 30.11.2014. ISJ Theoretical \&Applied Science 11(19): 51-54 Southampton, UK. doi: http://dx.doi.org/10.15863/TAS.2014.11.19.10

11. Ngo VA (2014) Modeli i algoritmy upravleniâ podgotovkoj magistrov $\mathrm{V}$ obrazovatel'nyh učreždeniâh požarno-tehničeskogo profilâ [Tekst]: avto-ref.dis. ... kand. teh. nauk: 05.13.10 / V.A. Ngo.- Moskva, 2014. - 24 p. 